\title{
The Effect of Hydraulic Hysteresis on the Shear Strength of Clayey Soils under Partially Saturated States
}

\author{
Lu Haifeng ${ }^{1,2, a}$, Chen Pan ${ }^{1, b}$ \\ 'State Key Laboratory of Geomechanics and Geotechnical Engineering, Institute of Rock and Soil \\ Mechanics, Chinese Academy of Sciences, Wuhan, Hubei 430071, China; \\ 2University of Chinese Academy of Sciences Beijing 100049, China \\ a799894951@qq.com, bpchen@whrsm.ac.cn
}

\begin{abstract}
Keywords: Unsaturated soil; soil-water retention; hydraulic hysteresis; clayey soil; shear strength Abstract. Hydraulic hysteresis is a common phenomenon in unsaturated soils. The soil-water retention curve from the drying process is different from the one from the wetting process due to the effect of hydraulic hysteresis. The soil strength is strongly affected by the soil-water characteristics. Hence, hydraulic hysteresis can have an important effect on the shear strength of a soil. The direct shear tests under the drying and wetting conditions were done to explore the effect mechanism of the hydraulic paths on the shear strength of clayey soils. The results show that shear strengths of the clayey soils have the obviously peak values at low water contents for the drying paths. And the strain softening characteristics of the clayey soils are exhibited. However, the strain hardening is exhibited under high water content conditions for the drying paths. The strain hardening is always occurred for the wetting paths. The shear strengths of the clayey soils are obviously different from the wetting and drying paths although the water content of the samples and loaded normal stress are the same. The shear strength loss ratio, $\eta$ is introduced to quantify the difference of shear strength of clayey soils under different hydraulic paths. The shear strength loss ratio is between $8 \%$ and $18 \%$, which shows that hydraulic hysteresis has an important influence on the shear strength of clayey soils.
\end{abstract}

\section{Introduction}

The shear strength of unsaturated soils is important to the design and evaluation in engineering practice. The effect of water content on the strength characteristics of a soil has been attracted the attention from many scholars. The results show that water content is not a simple linear relationship to the shear strength of unsaturated soils. Many scholars have proposed the formula to describe the change of the shear strength in unsaturated soils ${ }^{[1-3]}$. However, the effect of hydraulic hysteresis of unsaturated soils on the soil strength are rarely considered ${ }^{[4]}$. The shear strengths of unsaturated soils are obviously different from the drying and wetting paths due to the effect of hydraulic hysteresis, with the same water content ( soil suction ) of unsaturated soils. The drying and wetting cycles in a soil are common under the repeated water changes or intermittent rainfall, in which the effect of hydraulic hysteresis can be occured. The shear strength of unsaturated soils is different under drying and wetting hydraulic paths. Hence, it is necessary to explore the relation between the water storage capacity of soil material and the variation of energy stored among soil particles during the drying and wetting cycles ${ }^{[5]}$. To explore the mechanism between shear strength and water content of unsaturated soils, many scholars have established the relationship between water content and shear strength, in which water content is used as the main variable. These models are very usefull in practical engineering. The power function between the total stress shear strength parameters and water content was developed by Miao ${ }^{[6]}$ for an expansive compacted soil. The results show that mechanical parameters of expansive soils change with the water content from the measured data from the direct shear tests ${ }^{[7]}$.

In this paper, the reasons of hydraulic hysteresis of soils are introduced firstly under drying and wetting conditions. Then, the direct tests under the drying and wetting conditions were done to explore the effect mechanism on the shear strength of clayey soils under different hydraulic paths. Finally, the measured data are analyzed and used to validate the empirical formula, which is useful for the development of unsaturated soils shear strength theory. 


\section{The Explaination of Hydraulic Hysteresis}

The hysteresis characteristics of the soil are reflected by the hysteresis of the soil water characteristic curve, and the concept of the lag is reflected by the relationship between the matrix suction and the water content in Fig.1. It can be seen from Fig. 1 that the horizontal dotted line for the same matrix suction,$\psi_{1}$, intersect wetting and drying lines at two different points which correspond to water content of $\theta_{1 w}$ and $\theta_{1 d}$, so we can obviously see the lag between soils. Due to a certain amount of closed bubbles coming into being in the wetting process of the soil, it will not reach the saturation condition $\left(\theta_{s}\right)$. Besides, the soil will expand or contracted slightly and inevitably in the process of its drying or wetting, which will change the fine soil grains and results in the difference between them. And the above phenomenon that water -soil characteristic lags in the drying and wetting process also can be interpreted by a simple model shown as the Fig. 2. As a matter of fact, the aperture of the enter close that connects some soil macro-pores are smaller than themselves, and it results in the so-called "bottleneck". So the difference between the shrinking directions in the wetting and drying process lead to the different water content, which causes the lagged phenomenon. Another important reason can interpret the water -soil characteristic lag is that the contact angle in the solidity-liquid-gas interface is very different in the drying and wetting process of the unsaturated soil. And the research sandy soils proposed by Kumar ${ }^{[8]}$, Letey ${ }^{[9]}$ and et al. show that the wet contact angle reaches up to value between $60^{\circ}$ and $80^{\circ}$.

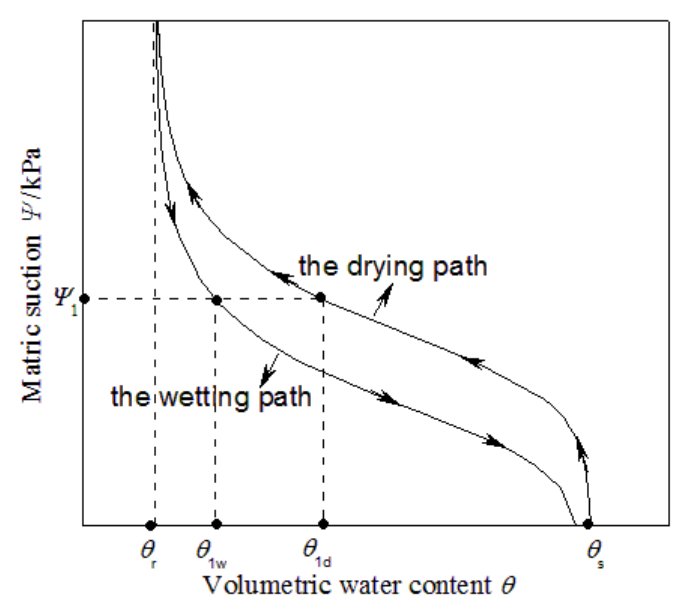

Fig. 1 Conceptual illustration of hysteresis of the soil water characteristic curve

Furthermore, the research by Laroussi and DeBacker ${ }^{[10]}$ shows that the range of wet contact angle is about $0^{\circ}$ to $20^{\circ}$ or $30^{\circ}$ which is much smaller than hygroscopic contact angle, and this phenomenon can be explained by the concept model of a water droplet on a solid surface. Under the influence of gravity, the leading edge of the water droplets forms a wet peak with the characteristic of big contact angle as the geometry reaching steady state. On the contrary, the drying peak is formed at the trailing edge of the water droplets with a small contact angle as shown in Figure 2. The differences between two kinds of contact angle have a great influence on the water holding capacity of unsaturated soil, and it is also an important factor leading to the lag of soil water characteristic curve and the suction stress characteristic curve, which has a further impact on the strength of the drying and wetting for unsaturated soil. Therefore, it is necessary to study the hydraulic hysteresis of soil. 


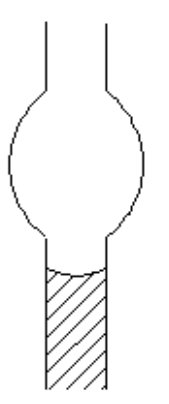

(a) wetting

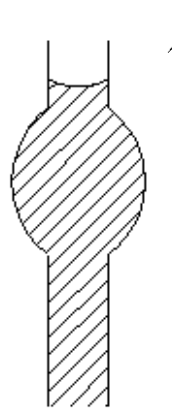

(b) drying

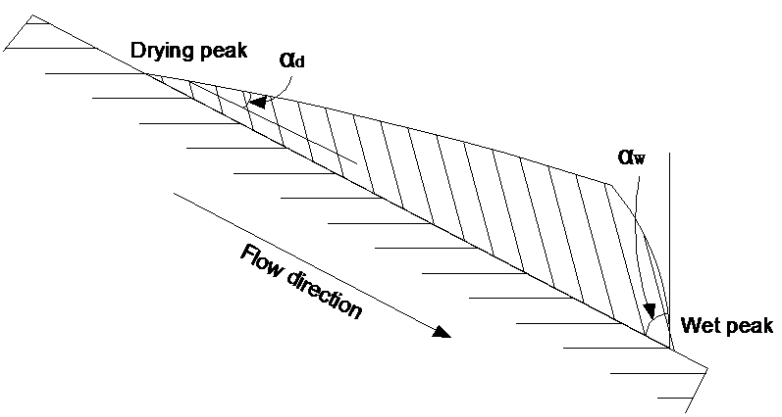

(c) water droplets on the sloping surface

Fig. 2 ink-bottle effect and contact angle hysteresis

\section{Materials and Methods}

The clay was taken from a highway of San Men Xia in He Nan,the main physical properties of indicators is in Table.1.

Table 1 The physical character index of silty clay

\begin{tabular}{ccccc}
\hline \multirow{2}{*}{ Soil } & $\begin{array}{c}\text { Initial water } \\
\text { Content } / \%\end{array}$ & $\begin{array}{c}\text { specific } \\
\text { gravity }\end{array}$ & $\begin{array}{c}\mathrm{I}_{\mathrm{L}} \\
1 \%\end{array}$ & $\begin{array}{c}\mathrm{IP}_{\mathrm{P}} \\
1 \%\end{array}$ \\
\hline silty clay & 5.1 & 2.74 & 36.2 & 19.4 \\
\hline
\end{tabular}

The test soil was treated according to the preparation method of perturbed soil samples according to the "Geotechnical Test Procedure" (SL237-1999) ${ }^{[11]}$. The test samples were reconstructed and the dry density was $1.6 \mathrm{~g} / \mathrm{cm} 3$. In order to ensure that the initial conditions of the soil is consistent, will be the first to make soil water content of eight percent test the clay, then with good soil made into ring knife sample again, part of the cutting ring samples through the vacuum pumping saturation, and then come out naturally dry, Time to take the quality, Meet the requirements of the water content of soil sample, sealed bag stand for $24 \mathrm{~h}$, made to take off the wet sample, and the other part of the ring knife through the burette, titration to the ring knife-like surface, in order to keep soil equally, the sample can be put into the moisturizing tank for 2 to 3 weeks, During this period according to get soil quality to prevent moisture to evaporate and replenish moisture, it is called the hygroscopic samples as reached a predetermined water content, Test by computer automatic control strain controlled quadruple direct shear apparatus, shear rate $0.8 \mathrm{~mm} / \mathrm{min}$. Take the same water content of four sample, the vertical pressure of $50 \mathrm{kPa}, 100 \mathrm{kPa}, 150$ $\mathrm{kPa}, 100 \mathrm{kPa}$ under the conditions of direct shear test, respectively.

\section{Results and Analysis}

The water contents of the tested samples were made up to $12 \%, 14 \%, 16 \%, 20 \%, 22 \%, 24 \%$ in the direct shear tests, respectively. The relationship between shear strain and shear stress of the clayey soil with different water content is obtained in Fig.3, and the solid and hollow marks represent the drying curve and the wetting curve, respectively. It can be seen from Fig. 3 that the shear strength of the drying path is higher than that of the wetting path under the same water content and loaded normal stress. The shear strength of the clayey soil is constantly decreasing with increase of water content. The shear strength of the clayey soil is obviously peaked in the range of low water content, and the strain softening characteristics are exhibited. Under the condition of high water content, the characteristics of strain hardening are exhibited, which indicates that moisture has an important effect on the shear strength in the unsaturated soils.

Because Moisture is mainly composed of adsorbed water, capillary water, free water in the soil. when the sample is made, there are more small pores due to the fact that the silty clay has more small particles, which produces more adsorbed water. Moisture is mainly preset in form of adsorbed water and capillary water in the range of low water content, which leads to chemical force (van der Waals force, capillary force, etc) enhanced. These forces cause the sample to exhibit a "hard" characteristic, which appears to be "brittle" when it is damaged, showing the characteristics of strain softening. 
Under the condition of high water content, the adsorbed water firm between soil particles is getting thicker, and gradually appear free water. The presence of free water increases the lubrication between soil particles and causes the silty clay to much softer, which shows the nature of the ductility in the destruction process. when the water content continues to increase, the softening phenomenon gradually weakened until it disappears.
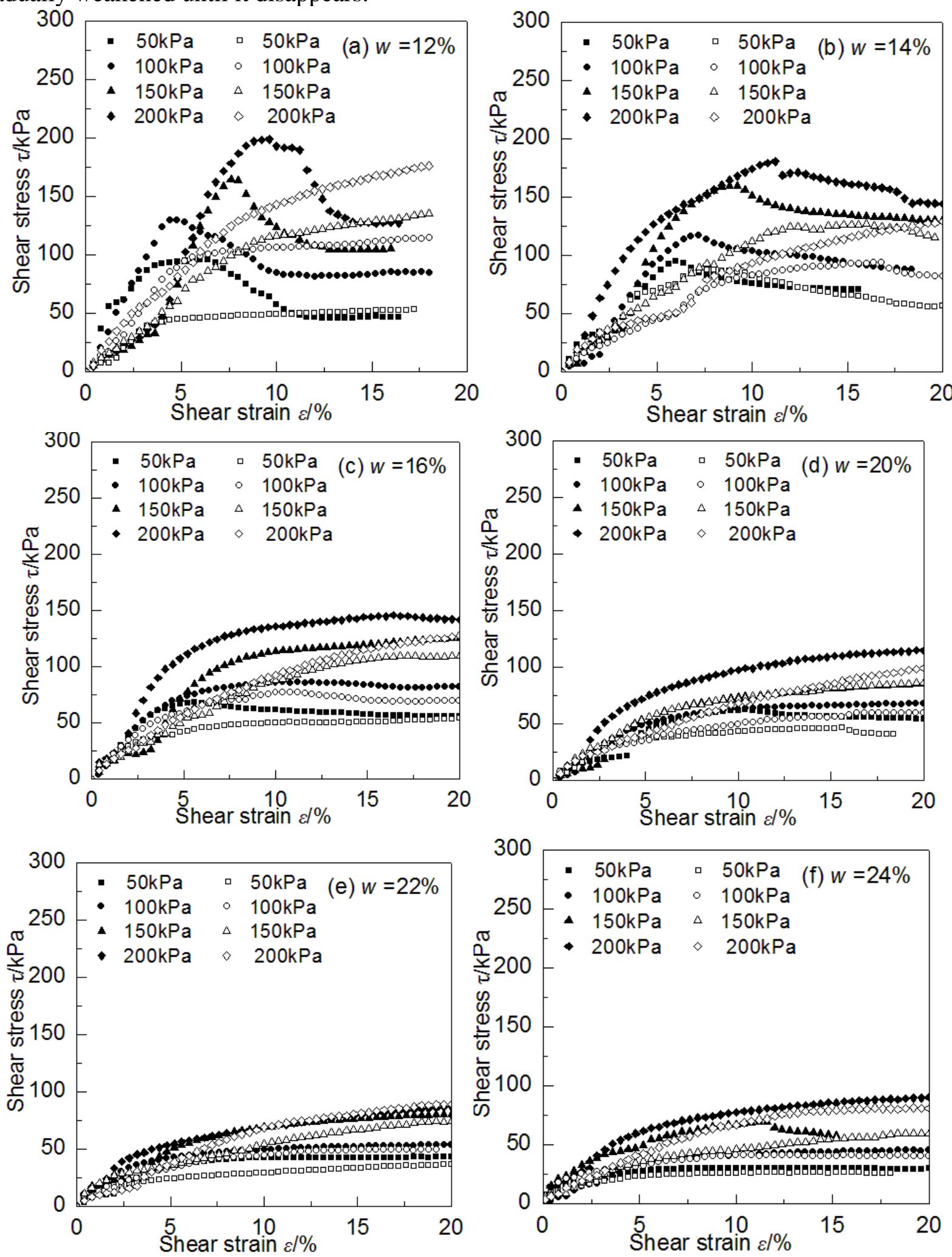

Fig. 3 The relation of shear strain and shear stress in the clayey soils under drying and wetting conditions 
Table 2 Shear strength parameters of the clayey soil with different water content under wetting and drying paths

\begin{tabular}{ccccccc}
\hline $\begin{array}{c}w \\
(\%)\end{array}$ & $\begin{array}{c}\rho_{d} \\
\left(\mathrm{~g} . \mathrm{cm}^{-3}\right. \\
)\end{array}$ & $\begin{array}{c}c_{w} \\
(\mathrm{kPa})\end{array}$ & $\begin{array}{c}\varphi_{w} \\
\left({ }^{\circ}\right)\end{array}$ & $\begin{array}{c}\rho_{d} \\
\left(\mathrm{~g} . \mathrm{cm}^{-3}\right)\end{array}$ & $\begin{array}{c}c_{d} \\
(\mathrm{kPa})\end{array}$ & $\begin{array}{c}\varphi_{d} \\
\left(^{\circ}\right)\end{array}$ \\
\hline 12.0 & 1.60 & 53.4 & 31.2 & 1.60 & 61.3 & 34.3 \\
14.0 & 1.60 & 48.6 & 26.9 & 1.60 & 53.4 & 32.2 \\
16.0 & 1.60 & 26.6 & 29.2 & 1.60 & 40.3 & 28.4 \\
20.0 & 1.60 & 18.1 & 22.5 & 1.60 & 22.3 & 24.9 \\
22.0 & 1.60 & 15.6 & 19.3 & 1.60 & 19.6 & 21.5 \\
24.0 & 1.60 & 15.3 & 17.9 & 1.60 & 15.8 & 19.2 \\
\hline
\end{tabular}
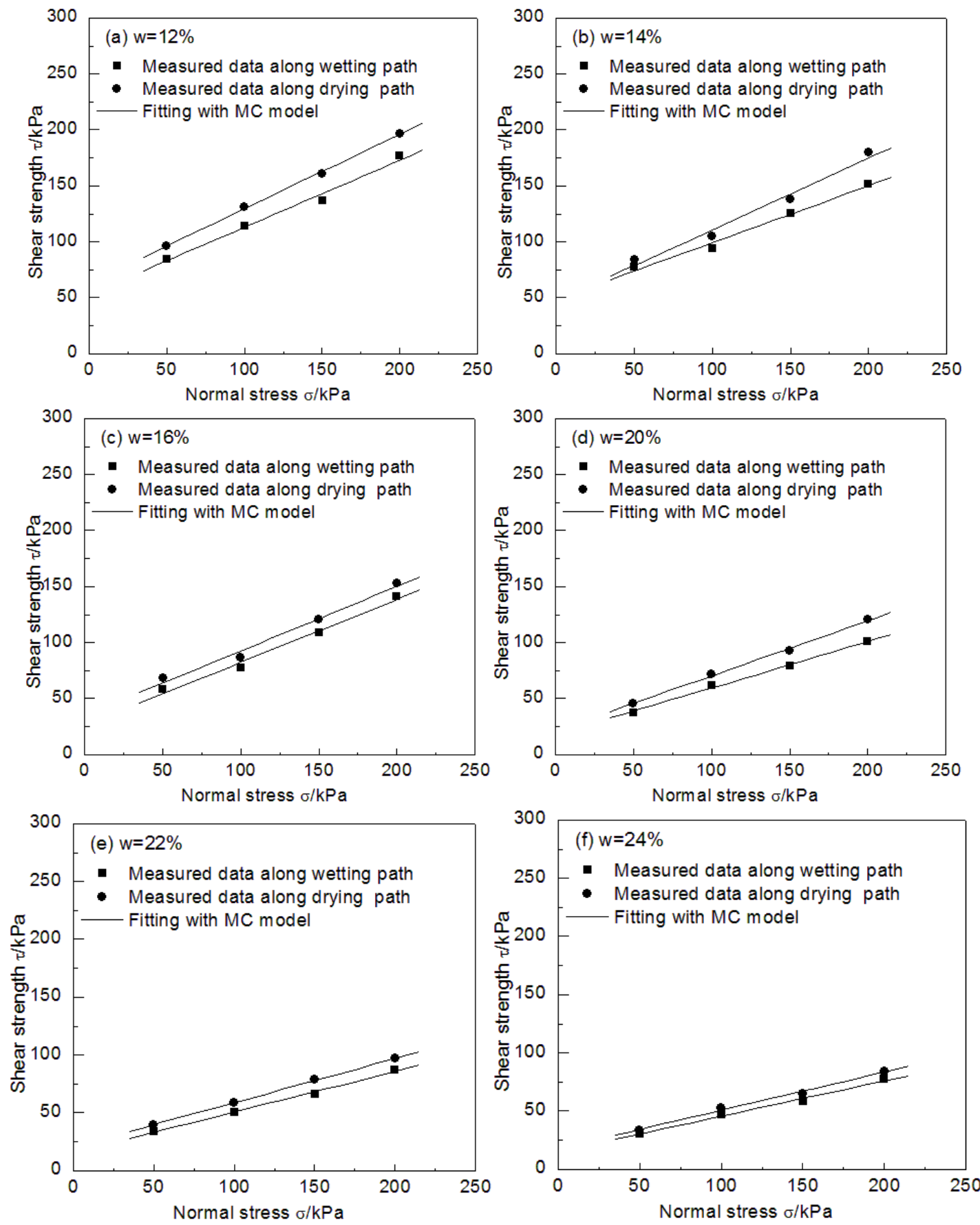

Fig. 4 The comparison for shear strength of the clayey soil under drying and wetting conditions 
Table 3 The differences of the shear strength-of clayey soils

\begin{tabular}{ccccc}
\hline Water content & \multicolumn{4}{c}{ Normal stress $\sigma / \mathrm{kPa}$} \\
$1 \%$ & 50 & 100 & 150 & 200 \\
\hline 12.0 & 11.9 & 12.9 & 15.1 & 10.3 \\
14.0 & 8.3 & 10.4 & 9.4 & 15.6 \\
16.0 & 14.6 & 10.4 & 9.1 & 7.8 \\
20.0 & 17.6 & 13.8 & 14.2 & 16.6 \\
22.0 & 15.2 & 13.6 & 15.3 & 10.3 \\
24.0 & 8.9 & 11.4 & 10.7 & 8.2 \\
\hline
\end{tabular}

By comparing the shear strength curves of the drying and wetting samples with different water content, the peak strength is obtained. When there is no obvious peak, the strength of $4 \mathrm{~mm}$ corresponding to the stress-strain curve is the breaking strength, and the shear strength of the two is compared in Fig.4, and the $c$ and $\varphi$ values in different water content (matrix suction) states were obtained using the Mohr-Coulomb intensity criterion and obtained in Table.2. It can be seen from Fig.4 that when the water content is the same, the shear strength of the clayey soils has a certain gap from the drying and wetting paths although water content of the samples and loaded normal stress are the same, and the shear strength of the drying path is higher than that of the wetting path. In order to quantify the shear strength between the two Gap, a shear strength loss ratio $\eta$ is introduced.

$$
\eta=\frac{\tau_{d}-\tau_{w}}{\tau_{d}} \times 100 \%
$$

where $\tau_{d}$ is the shear strength under the drying path, $\tau_{w}$ is the shear strength of the same water content and the same vertical stress under the wetting path.

the ratio between the strength of the drying path and the strength of the wetting path can be obtained in the case of changes in water content by the Eq. (1) as shown in Table 3, it can be seen from Table 3 that the ratio of shear strength loss under different water content and vertical stress is about $8 \% \sim 18 \%$, which indicates that the hydraulic hysteresis of soil has an important effect on the shear strength of soil. Fig.5 shows that, regardless of whether the soil is dehumidified or moisture absorption, unsaturated soil shear strength parameters are changes with the water content changes, the relationship of the effective cohesion and the water content is the decreased quadratic curve, the relationship of the effective internal friction angle and the water content is approximately linearly reduced. And the shear strength parameter can be expressed by the Eq. (2).

$$
\begin{aligned}
& c=a+b w+c w^{2} \\
& \varphi=d+f w
\end{aligned}
$$

where $a, b, c, d$, and $f$ is the fitting parameter and needs to be determined by experiment. The parameters of this test are shown in Table.4, which $c_{d}, \varphi_{d}$ is the shear strength parameter for the drying process and $c_{w}, \varphi_{w}$ is the shear strength parameter for the wetting process
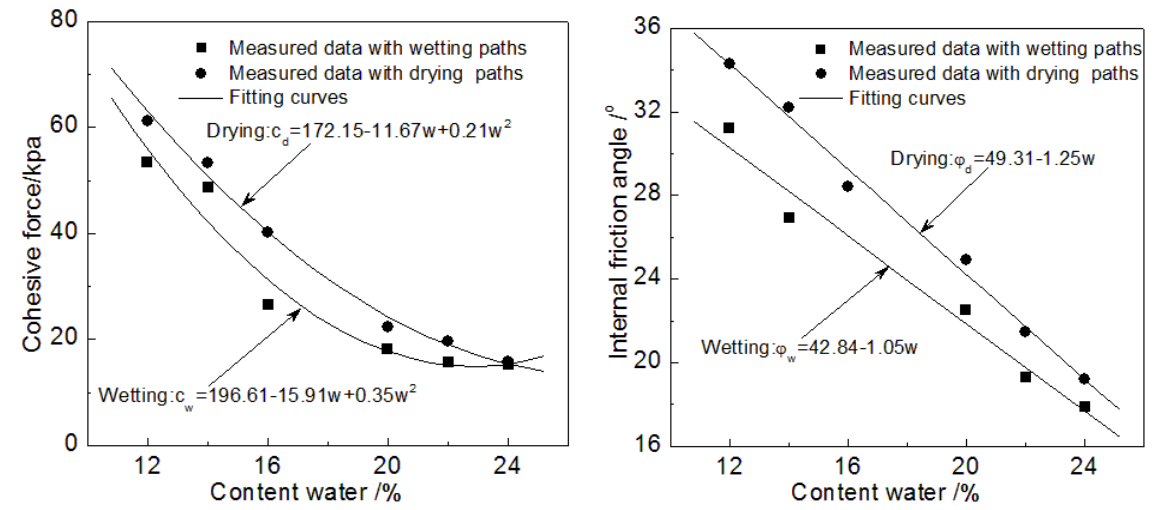

Fig. 5 The change of shear strength parameters in the clayey soil with different water content conditions during drying and wetting 
Table 4 Fitting the parameters under the drying and wetting paths

\begin{tabular}{cll}
\hline \multirow{2}{*}{ Wetting path } & $c_{w}=196.61-15.91 w+0.35 w^{2}$ & $R^{2}=0.953$ \\
& $\varphi_{w}=42.84-1.05 w$ & $R^{2}=0.972$ \\
\hline \multirow{2}{*}{ Drying path } & $c_{d}=172.15-11.67 w+0.21 w^{2}$ & $R^{2}=0.982$ \\
& $\varphi_{d}=49.31-1.25 w$ & $R^{2}=0.987$ \\
\hline
\end{tabular}

\section{Conclusions}

The authors carried out the direct shear test on the clayey samples under the wetting and drying paths with different water contents. The main conclusions are summarized as follows:

(1) The direct shear strength under the drying and wetting conditions were done, in which the results show that the peak value of shear strength occurs under the lower water content for the drying paths. The strain softening characteristic is demonstrated during the shear process, whereas the strain hardening characteristic is show under higher water content for the drying paths.

(2) The results show that the shear strength of the clayey soils has obvious differences from the drying and wetting paths. The shear strength loss ratio loss ratio, $\eta$ is introduced to quantify the difference, which is between $8 \%$ and $18 \%$.

(3) The shear strength parameters of unsaturated clayey soil are affected by the water content, regardless of the effect of dehumidified or moisture absorption. The fitted relation of the effective cohesion and the water content is the decreased quadratic curve. And the fitted relation of the effective internal friction angle and the water content is approximately linearly reduced curve.

\section{Acknowledgements}

The authors extend my sincere gratitude to assitant professor Chen Pan for his constant support throughout my work on this thesis and for his informed guidance and advice.

\section{References}

[1] A.W Bishop, G.E.Blight. Some aspects of effective stress in saturated and partly saturated soils [J]. Geotechnique, Vol.177-197(1963),p.13(3)

[2] D.G.Fredlund, N.R.Morgenstern, and R.A.Widger The shear strength of unsaturated soils. Canadian Geotechnical Journal, Vol.313-321(1978), p.15.

[3] N.Lu, J.W.Godt,and D. T.Wu. A closed-form equation for effective stress in unsaturated soil . Water Resource. Research, (2010), p.46,

[4] Biwei Gongi,Xiaowen Zhou, Zhou,Wuhua Zhou .Test on suction and strength of expansive soil in a desorption-absorption cycle of moisture.Chinese Journal of Geotechnical Engineering,Vol.207- 209(2006),p.28(2) (In Chinese)

[5] Li X S. Modeling of hysteresis response for arbitrary wetting / drying paths . Computers and Geotechnics,Vol. 133-137(2005),p.32(2).

[6] Linchang Miao. Relationship between strength and water content of expansive soil. Rock and Soil Mechanics,Vol. 71-75(1999),p.20(2).(in Chinese)

[7] Heping Yang, Rui Zhang, Jianlong Zheng. Variation of the total shear strength of unsaturated expansive soils with degree of saturation.China Civil Engineering Journal,Vol. 58-62(2006),p.39(4).(In Chinese)

[8] S.Kumar and R.S.Malik .Verification of quick capillarity rise approach for determining pore geometrical characteristic in soils of varying texture.Soil Science, 1990,150(6):883-888. 
[9] J. Letey,J. Osborn,R.E.Pelishek.Measurement of liquid-solid contact angle in soil and sand.Soil Science, Vol. 149-153(1962).p.93.

[10] C.H. Laroussi, L.W. Debacker .Relation between geometrical properties of glass bead media and their main $\psi^{(\theta)}$ hysteresis loops.Soil Science of America Journal,Vol. 646-650(1979),p.43.

[11] The Ministry of Water Resources of the People's Republic of China. Specification of soil test [S]. SL237-1999(1999). (in Chinese) 